\title{
Avoiding the Hazards of Ultraviolet Light in the Adolescent Population
}

\author{
Alexander Auchus ${ }^{1}$, Robert T. Brodell, MD², Vinayak K. Nahar, MD, MS, PhD, FRSPH ${ }^{2,3}$, \\ Kimberley H.M. Ward, MD² \\ ${ }^{1}$ Department of Psychology, School of Arts and Sciences, University of Pennsylvania, Philadelphia, PA \\ ${ }^{2}$ Department of Dermatology, School of Medicine, University of Mississippi Medical Center, Jackson, MS \\ ${ }^{3}$ Department of Preventive Medicine, School of Medicine, University of Mississippi Medical Center, Jackson, MS
}

\section{ABSTRACT}

Exposure to UV light remains the major modifiable risk factor for skin cancer. Studies have shown that adolescents do not adequately use sun protection and frequently engage in tanning behaviors. This article will reinforce approaches to avoid the hazards of UV light and provide tips and tricks that health care providers should emphasize to their adolescent patients.

\section{INTRODUCTION}

Ultraviolet (UV) light in the UVB and UVA ranges has been demonstrated to cause acute sunburn and chronic skin problems including wrinkles, brown spots (solar lentigines), sallowness, precancerous lesions including actinic keratoses, and skin cancer (basal cell carcinoma, squamous cell carcinoma, and melanoma). ${ }^{1-4}$ In fact, in 2009, UV-emitting tanning devices were classified as "carcinogenic to humans" (Group 1) by the World Health Organization's International Agency for Research on Cancer. ${ }^{5}$ Skin damage is increased with the strength of the UV light during mid-day (10am-2pm), cloudless days, higher altitudes, and the duration of exposure.

The time to start protecting the skin from the hazards of UV is during childhood. Many individuals receive half of their lifetime sun damage before age $18{ }^{6}$ Sports and other outdoor recreational activities increase UV exposure. In addition, the widely held belief that tanned skin is beautiful motivates young people to use natural and artificial light to tan. Many young people also feel a sense of invincibility that makes it difficult to convince them to protect themselves from ultraviolet radiation (UVR). While not everyone exposed to significant amounts of UV light will develop skin cancer, the lifetime risk of basal cell carcinoma in Caucasian individuals is around $30 \%{ }^{7}$ Most importantly, one severe sunburn in a lifetime has been shown to increase an individual's risk of developing potentially life-threatening malignant melanoma. ${ }^{8,9}$

Protection from the hazards of UV light remains the most important modifiable risk factor for skin cancer. This article will reinforce approaches to avoid the hazards of 
tanning and provide tips and tricks that health care providers should provide to their adolescent patients.

\section{PROBLEMS + PRACTICAL SOLUTIONS}

\section{Avoid Artificial UV Exposure}

Unfortunately, "even one indoor tanning session can increase users' risk of developing melanoma by 20 percent, squamous cell carcinoma by 67 percent and basal cell carcinoma by 29 percent" according to the American Academy of Dermatology. Thus, our patients should be encouraged to avoid all artificial UV tanning devices. Advocacy efforts should promote state laws that prohibit tanning of youth under age 18. A number of states already have such laws (Figure 1).

\section{Protection from Outdoor UV light}

Adolescents should avoid the peak mid-day sun and seek shade structures when available. In addition, they should shield their skin from UVR using the following evidence-based techniques.

Hats

The most convenient way to protect the face and neck from UVR is to wear a widebrimmed hat. Unfortunately, the most commonly worn hat is a baseball cap. These flat or peak capped hats provide minimal UVR protection for the ears, cheek, chin, and back of neck as seen in Table 1 .

\section{A baseball (peaked) cap does not} provide significant $U V$ protection to the ears, cheeks, chin, and back of the neck.

While large brimmed hats $(>7.5 \mathrm{~cm})$ are recommended for all individuals, these hats still provide less than a sun protection factor (SPF) 10 to the nose, cheek, chin, and back of neck; therefore, sunscreen should be worn with the hat. ${ }^{10}$ Visors used over hard hats by workers are also adaptable to various helmets used in sports (See Figure 2).

\section{Protective Clothing}

The use of protective clothing is as important as using a hat in shielding areas of the body from direct UV exposure. ${ }^{11}$ Bikinis and men's brief style swimsuits expose more skin to the sun than one-piece women's suits and men's jammer styles that cover the thighs. Wearing light-colored, long-sleeved shirts is also recommended because individuals who wear protective clothing have been shown to suffer fewer sunburns when compared to individuals who apply sunscreen alone. ${ }^{12}$

Adolescents should be encouraged to wear UVR blocking clothing; denim, cotton, nylon, and polyester are some of the most effective UVA and UVB protective fabrics currently available on the market. ${ }^{11}$ Protective clothing should be worn even in the water at the pool or beach, but it should be noted that cotton fabric transmits UV light to underlying skin much more effectively when wet. $^{13}$ Physicians should also recommend clothing labeled with ultraviolet protection factors (UPFs) as an easy way to ensure that the chosen clothing will be effective UVR blockers. Clothing with a UPF of 30 , for example, protects the skin from all but $1 / 30$ th of UV radiation.

UV blocking clothing is an important component to avoiding the hazards of UV light exposure

Sunscreens

Sunscreen should also be used in conjunction with protective clothing in order

May 2020 Volume 4 Issue 3 


\section{SKIN}

Figure 1. Map of State Laws Prohibiting Minors from Using Tanning Devices

State Laws Prohibiting Minors from Using Tanning Devices

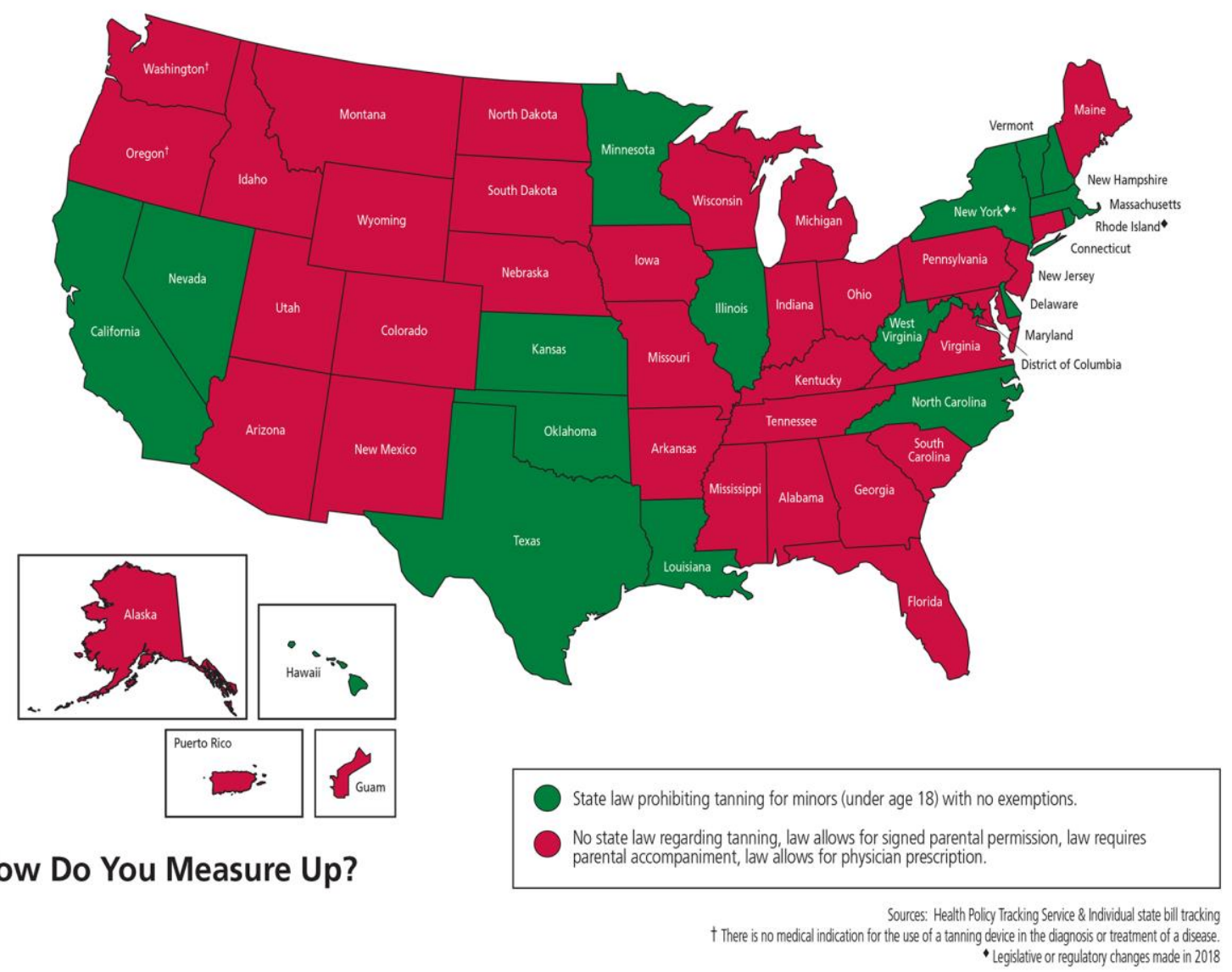

Figure 2. Type of UV protective head gear classified by brim.

\begin{tabular}{|c|c|c|c|c|}
\hline Peaked cap & Small brim & Medium brim & Large brim & $\begin{array}{c}\text { Hard Hat Sun } \\
\text { Visor }\end{array}$ \\
\hline & &
\end{tabular}


to more completely protect the skin from the hazards of UVR. As an example of the efficacy of this multifaceted recommendation, the famous Australian Slip! Slap! Slop! (Slip on a shirt, slap on a hat, and slop on sunscreen) campaign resulted in significant positive changes in attitudes toward sun tanning in Australia resulting in decreased rates of melanoma. ${ }^{14}$ A broad-spectrum, water-resistant sunscreen with an SPF of 30 or greater should be recommended for its ability to protect the skin from sunburn, premature photoaging, and precancerous sun damage. ${ }^{15}$ An SPF of 30 implies that individuals can stay in the sun for 30 times longer with the product than without the product to receive the same amount of UVR. Some products are more substantive, that is, they resist washing off when sweating or in the water. These formulations are termed "water-resistant" since the FDA will no longer allow labeling as "water proof". ${ }^{16}$ It is important to note that at least one ounce of sunscreen is needed to effectively cover the entire body of an average sized adult and that sunscreen should be reapplied about every two hours or more often if sweating or in water. ${ }^{17}$ Patients should also be advised to take the time necessary to distribute sunscreen evenly across the entirety of the exposed skin, as hasty sunscreen application results in uneven protection. ${ }^{18}$
In order to address this issue, some resorts have installed sunscreen booths that spray sunscreen evenly over the entire body with minimal effort. ${ }^{19}$

\section{A broad spectrum (UVA and UVB) blocking sunscreen with an SPF greater than 30 should be recommended for routine use outdoors}

In general, because chemical agents have reduced photostability, ${ }^{20}$ chemical sunscreens may necessitate more frequent reapplication. Conversely, physical agents are desirable because they provide broadspectrum UV protection and are completely photostable. ${ }^{20}$ However, physical agents often leave a visible white residue on the skin. They also remain on the skin longer than many chemical agents and thus may be more difficult to remove. A wide range of sunscreens products with chemical and physical sunscreen agents are available in the U.S. market. These sunscreen agents offer certain advantages and disadvantages (See Table 2).

Considering the range of cream, lotion, gel, spray, stick, oil, and powdered products that are available, we recommend that patients choose the sunscreen they like best so long as it has an SPF of 30 or greater.

Table 1. Summary of sun-protection factors at various sites on the head and neck provided by different types of hats.

\begin{tabular}{|llllll|}
\hline & \multicolumn{2}{l}{ Typical sun-protection factor } & & \\
\hline Style of hat & Forehead & Nose & Cheek & Chin & Back of neck \\
\hline Small brim $(<\mathbf{2 . 5} \mathbf{~ c m})$ & 15 & 1.5 & 1 & 1 & 1 \\
\hline Medium brim $(\mathbf{2 . 5} \mathbf{- 7 . 5} \mathbf{~ c m})$ & $>20$ & 3 & 2 & 1 & 2 \\
\hline Large brim $(>\mathbf{7 . 5} \mathbf{~ c m})$ & $>20$ & 7 & 3 & 1.2 & 5 \\
\hline Peaked cap & $>20$ & 5 & 1.5 & 1 & 1 \\
\hline
\end{tabular}


People are more likely to use the product that they like; the benefits of routinely using a favorite product overshadow the potential benefits of using one recommended product. For now, it is abundantly clear that sunscreens as part of a multi-modal effort can reduce actinic keratoses, skin cancers, wrinkles, and solar lentigines.

\section{Patients should choose the sunscreen they like among available products with SPF 30 or greater}

\section{Responding to Challenging Patient Questions}

Some patients resist wearing sunscreen for very specific reasons. Health care providers should be prepared to respond to the following issues often raised by patients:

\section{Physicians should be prepared to} answer the specific reasons patients present to explain their lack of adherence to recommended sunscreen use

\section{1) "It leaves a white residue"}

White residue results from the physical sunscreen agents titanium dioxide and zinc oxide. Even micronized formulations can be difficult to rub into the skin and often leave a white powdery residue. Despite this drawback, they provide a broad-spectrum, high SPF and are often quite substantive. In other words, they do not wash off easily when swimming or sweating. Although not as substantive, chemical sunscreens are alternatives that do not usually leave white residue.
2) "It contains dangerous nanoparticles." Micronized physical sunscreens do contain nanoparticles. There is ongoing research regarding potential side effects of these products, but studies to date demonstrate minimal systemic absorption. ${ }^{23,24}$ The FDA would not allow these products to remain on the market if there was evidence of significant toxicity. Additionally, chemical sunscreen agents do not contain nanoparticles and can be used as alternatives to nanoparticle physical sunscreens if desired.

\section{3) "It stings my eyes."}

Chemical sunscreens are more likely to cause stinging of the eyes when sweating causes them to flow into the eyes from the forehead. ${ }^{25}$ Physical sunscreens generally do not cause this side effect and may be appropriate for athletes who complain of this problem.

\section{4) "It causes cancer."}

There is evidence that urocanic acid, a sunscreen agent previously used in Europe, may be carcinogenic. ${ }^{26}$ However, this agent was never used in sunscreen formulations in the U.S.A. In fact, none of the currently FDA approved sunscreen agents are carcinogenic. There is also no evidence that sunscreen agents are harming humans in the concentrations to which we are exposed. ${ }^{27}$ A second mechanism has also been postulated whereby sunscreen could "cause cancer:" Wearing UVB blocking sunscreen alone without UVA protection could result in individuals remaining in the sun for longer periods of time, thus accumulating more significant UVA damage. UVA penetrates the skin more deeply and may be particularly associated with solar elastosis and malignant melanoma. However, physicians recommend using a broad-spectrum sunscreen that protects against both UVA and UVB rays in

May 2020 Volume 4 Issue 3 
Table 2. "Sunscreen agents: range covered, advantages, and disadvantages"

\begin{tabular}{|c|c|c|c|}
\hline $\begin{array}{l}\text { Chemical Sunscreen } \\
\text { Agent }\end{array}$ & $\begin{array}{l}\text { Range Covered }{ }^{21} \\
\text { UVA1: } 340-400 \mathrm{~nm} \\
\text { UVA2: } 320-340 \mathrm{~nm} \\
\text { UVB: } 290-320 \mathrm{~nm}\end{array}$ & Advantages & Disadvantages \\
\hline $\begin{array}{l}\text { Aminobenzoic acid } \\
\text { (PABA) }\end{array}$ & UVB & $\begin{array}{l}\text { Long lasting } \\
\text { (penetrates horny } \\
\text { layer). }{ }^{22}\end{array}$ & $\begin{array}{l}\text { Can stain clothing } \\
\text { Can cause allergic or } \\
\text { photoallergic dermatitis. }{ }^{22}\end{array}$ \\
\hline Avobenzone & UVA1 & & $\begin{array}{l}\text { Can cause allergic and } \\
\text { photoallergic reactions. }\end{array}$ \\
\hline Cinoxate & UVB & & $\begin{array}{l}\text { Rarely causes } \\
\text { photoallergic contact } \\
\text { dermatitis. }{ }^{22}\end{array}$ \\
\hline Dioxybenzone & UVB, UVA2 & & $\begin{array}{l}\text { May cause allergic contact } \\
\text { dermatitis. }{ }^{22}\end{array}$ \\
\hline $\begin{array}{l}\text { Ecamsule (Mexoryl } \\
\text { SX) }\end{array}$ & UVA2 & & $\begin{array}{l}\text { Can cause allergic and } \\
\text { photoallergic reactions. }^{22}\end{array}$ \\
\hline $\begin{array}{l}\text { Ensulizole } \\
\text { (Phenylbenzimiazole } \\
\text { Sulfonic Acid) }\end{array}$ & UVB & & $\begin{array}{l}\text { Can cause allergic and } \\
\text { photoallergic reactions. }^{22}\end{array}$ \\
\hline Homosalate & UVB & & $\begin{array}{l}\text { Can cause photoallergic } \\
\text { reactions. }{ }^{22}\end{array}$ \\
\hline $\begin{array}{l}\text { Meradimate } \\
\text { (Menthyl } \\
\text { Anthranilate) }\end{array}$ & UVA2 & & $\begin{array}{l}\text { May cause irritant, allergic, } \\
\text { and photoallergic } \\
\text { reactions. }{ }^{22}\end{array}$ \\
\hline Octocrylene & UVB & & $\begin{array}{l}\text { Can cause allergic and } \\
\text { photoallergic reactions. }^{22}\end{array}$ \\
\hline $\begin{array}{l}\text { Octinoxate (Octyl } \\
\text { Methoxycinnamate) }\end{array}$ & UVB & $\begin{array}{l}\text { Poor water } \\
\text { solubility (water- } \\
\text { resistant). }{ }^{22}\end{array}$ & $\begin{array}{l}\text { Commonly causes allergic } \\
\text { and photoallergic } \\
\text { reactions. }{ }^{22} \\
\text { Possible cross-reactivity } \\
\text { with flavorings and } \\
\text { fragrances. }{ }^{22}\end{array}$ \\
\hline $\begin{array}{l}\text { Octisalate (Octyl } \\
\text { Salicylate) }\end{array}$ & UVB & & $\begin{array}{l}\text { Can cause all } 4 \text { types of } \\
\text { contact dermatitis. }^{22}\end{array}$ \\
\hline Oxybenzone & UVB, UVA2 & & $\begin{array}{l}\text { Commonly causes } \\
\text { irritant, allergic, and } \\
\text { photoallergic dermatitis. }{ }^{22} \\
\text { May induce photo contact } \\
\text { urticaria, contact urticaria, } \\
\text { and anaphylaxis. }{ }^{22} \\
\text { Nonsteroidal anti- } \\
\text { inflammatory drugs may }_{\text {cross-react. }}^{22}\end{array}$ \\
\hline
\end{tabular}




\begin{tabular}{|c|c|c|c|}
\hline Padimate $\mathbf{O}$ & UVB & & $\begin{array}{l}\text { Can cause photoallergic } \\
\text { contact dermatitis. }^{22}\end{array}$ \\
\hline Sulisobenzone & UVB, UVA2 & & $\begin{array}{l}\text { Can cause all } 4 \text { types of } \\
\text { contact dermatitis. } \\
\text { May cause urticarial } \\
\text { reactions. }\end{array}$ \\
\hline Trolamine Salicylate & UVB & & $\begin{array}{l}\text { May cause allergic } \\
\text { reactions. }{ }^{22}\end{array}$ \\
\hline \multicolumn{4}{|l|}{$\begin{array}{l}\text { Physical Sunscreen } \\
\text { Agent }\end{array}$} \\
\hline Titanium Dioxide & UVB, UVA2 & & Difficult to rub in. \\
\hline Zinc Oxide & UVB, UVA2, UVA1 & $\begin{array}{l}\text { Offers } \\
\text { comprehensive } \\
\text { UV protection. }\end{array}$ & Difficult to rub in. \\
\hline $\begin{array}{l}\text { Micronized Zinc } \\
\text { Oxide }\end{array}$ & UVB, UVA2, UVA1 & $\begin{array}{l}\text { Offers } \\
\text { comprehensive } \\
\text { UV protection. } \\
\text { Easier to rub in. }\end{array}$ & \\
\hline $\begin{array}{l}\text { Micronized Titanium } \\
\text { Dioxide }\end{array}$ & UVB, UVA2 & Easier to rub in. & \\
\hline
\end{tabular}

conjunction with hats, protective clothing, and seeking shade when possible. Thus, this fear is tenuous at best.

\section{5) "It hurts the environment"}

Recent evidence suggests that the chemical sunscreen ingredient oxybenzone/benzophenone-3 and related sunscreens may have a toxicological impact on the environment. The facts are: 1) minute amounts of oxybenzone from sunscreen use and manufacture is detectable in oceans, swimming pools, and lakes; 2) oxybenzone can destroy coral by bleaching; and 3) 4-methylbenzylidene camphor, oxybenzone, octocrylene and octinoxate have been identified in fish. ${ }^{27}$ With regard to coral, studies have shown damage to coral in the immediate vicinity of beaches where sunscreens are worn by thousands of swimmers. ${ }^{27}$ However, only about $10 \%$ of global reefs and up to $40 \%$ of coastal reefs are at risk for coral bleaching. ${ }^{28}$ With this in mind, and recognizing that no perfect sunscreen exists, banning the use of these products is premature. If a more significant threat to the coral reef ecosystem is proven, this could be reconsidered.

\section{6) "I am allergic to sunscreen."}

Chemical sunscreens are generally less well tolerated when compared to physical agents. Many chemical agents produce allergic or photoallergic reactions including: Aminobenzoic acid (PABA), avobenzone, dioxybenzone, ecamsule (Mexoryl SX), ensulizole (phenylbenzimiazole sulfonic acid), homosalate, meradimate (menthyl anthranilate), octocrylene, octinoxate (octyl methoxycinnamate), octisalate (octyl salicylate), oxybenzone, padimate 0 , sulisobenzone, and trolamine salicylate. ${ }^{22}$ For patients experiencing allergic reactions 
to a sunscreen, they can try sunscreens containing different chemicals or use physical agents. Of course, it is possible for individuals to be allergic to preservatives or fragrances used in any sunscreen product. Patch testing can define the specific ingredients causing allergic contact dermatitis and a simple switch to a physical sunscreen should eliminate this problem. ${ }^{22}$

\section{7) "I will get vitamin $D$ deficiency and develop weak bones."}

For individuals worried about their vitamin $\mathrm{D}$ levels, it is recommended that they ingest 2000 international units (IU) of vitamin D daily from food, dietary supplements, or both. Damaging the skin with UV is not required to maintain adequate vitamin $D$ levels.

\section{Sunless Methods of Tanning}

While some experts suggest that sunless tanning products should be avoided because they glorify tanning, we favor this safe alternative to achieving the "tan look" versus UV damage to the skin. Of course, adolescents should be warned that sunless tanning products provide negligible sun protection and can even increase one's susceptibility to UV-induced free radicals. ${ }^{29}$
Thus, it is imperative that sunscreen and other sun protective behaviors be employed

\section{Sunless tanning products represent a safe way to "look tan."}

when using sunless tanning products. There are two categories of topical sunless tanning products. First, the sugars dihydroxyacetone and erythrulose produce a "Maillard reaction" in the outer layers of the stratum corneum and epidermis, which results in a tan appearance. ${ }^{30}$ These products are topically applied daily until the desired color is achieved and then are reapplied as needed (usually weekly). The second category, bronzing products, consists of water-soluble pigments that produce a temporary tanned appearance until they are washed off. These pigments are commonly used in makeup and tinted lotions. Table 3 describes the various sunless tanning agents available in the U.S. market.

\section{Motivation}

Despite proper warning and instruction, many adolescents will choose not to engage in sun protective behaviors in favor of "beautiful," tanned skin. One approach is to warn adolescents that UV causes DNA

Table 3. Sunless tanning agents: advantages and disadvantages

\begin{tabular}{|c|c|c|}
\hline Tanning Agent & Advantages & Disadvantages \\
\hline $\begin{array}{l}\text { DHA } \\
\text { (dihydroxyacetone) }\end{array}$ & $\begin{array}{l}\text { Produces a tan color that } \\
\text { lasts about a week. }{ }^{31}\end{array}$ & $\begin{array}{l}\text { Can induce UV-generated free radicals } \\
\text { in the skin. }{ }^{29} \\
\text { Can produce a streaky or blotchy color. }\end{array}$ \\
\hline Erythrulose & $\begin{array}{l}\text { When used with DHA, the } \\
\text { color produced reportedly } \\
\text { lasts longer and has a more } \\
\text { natural tone. } .^{32}\end{array}$ & $\begin{array}{l}\text { Color produced may be tinted yellow or } \\
\text { red. }{ }^{29} \\
\text { Produces a more temporary color than } \\
\text { DHA. }{ }^{32} \\
\text { Can produce a streaky or blotchy color. }\end{array}$ \\
\hline $\begin{array}{l}\text { Water Soluble } \\
\text { Pigments }\end{array}$ & $\begin{array}{l}\text { Allow for more even } \\
\text { application. }\end{array}$ & $\begin{array}{l}\text { Last about } 24 \text { hours or until washed } \\
\text { off. }{ }^{30}\end{array}$ \\
\hline
\end{tabular}


damage and thus predisposes one to a higher risk of skin cancer. ${ }^{33}$ However, studies suggest that adolescents do not believe or do not care that they will develop skin cancer. Instead of this approach, we favor warning adolescents about the deleterious effects of UVR on the appearance of one's skin. ${ }^{34}$ Adolescents must be warned that while not everyone with sun-damaged skin will get skin cancer, $100 \%$ will have sallowness, wrinkles, loss of elasticity, and brown spots. One study demonstrated a significant increase in sunscreen use among a group of adolescents who were shown a video explaining the appearance-based consequences of UVR. The group shown a similar video describing the health-based consequences of UVR did not see an increase in sunscreen use. ${ }^{35}$ In another controlled study, college-aged females tanned less often after receiving a workbook describing the damaging effects of indoor tanning on the skin's appearance. ${ }^{36}$ Similarly, adolescents had intentions to use both sunscreen and other forms of sun when shown pictures of unsightly skin discoloration on areas of the face and neck that resulted from a lack of sun protection. ${ }^{37}$ Finally, the Sunface ${ }^{\mathrm{TM}}$ mobile application edits facial images to highlight the potential effects of photoaging. A 2017 pilot study demonstrated that $63 \%$ of participants agreed that the edited picture "motivated them to avoid using a tanning bed" and $62 \%$ agreed "to increase use of sun protection". 38 Thus, appearance-based fear tactics are effective in improving adherence of sun protective behaviors in young people. ${ }^{34,35}$

The effects of UV on appearance may motivate our patients more effectively than fear of developing cancer
Even when adolescents adopt sun protective behaviors, it has been shown that they do not maintain their efforts over time. Text-message reminders to wear sunscreen, long sleeves, and hats may serve to encourage adolescents to protect themselves from the sun. For example, one 6-week study of 70 participants showed that those in the experimental group who received daily text-message reminders to wear sunscreen had significantly higher rates of adherence compared to those in the control group. ${ }^{39}$

\section{CONCLUSION}

In summary, it is abundantly clear that sunscreens should play a part in a multimodal effort to reduce actinic keratoses, skin cancers, wrinkles and solar lentigines. Adolescents and their parents are critical targets for education efforts to reduce skin damage from UVR. Physicians play an integral role in this process by promoting healthy habits and stressing that there is no safe amount of UV tanning.

Conflict of Interest Disclosures:

Robert Brodell, M.D. discloses the following potential conflicts of interest: Multicenter Clinical Trials:

Galderma Laboratories, L.P. - Principal Investigator; Novartis Principal Investigator; and, Glaxo Smith Kline - Principal Investigator; Editorial Boards: American Medical Student Research Journal;

Practice Update Dermatology; Practical Dermatology; Practical Dermatology; Journal of the Mississippi

State Medical Society; SKIN: The Journal of Cutaneous Medicine and, Journal of the American Academy of Dermatology. There are no conflicts of interest related to employment, stock ownership, expert testimony, grants, patents filed, received, pending, or in preparation, or royalties.

Alexander Auchus, Vinayak K. Nahar, and Kimberly Ward have no conflicts of interest

Funding: None 
Corresponding Author:

Vinayak K. Nahar, MD, MS, PhD, FRSPH

Department of Dermatology

University of Mississippi Medical Center

2500 North State Street - L216

Jackson, MS 39216 USA

Phone: 601-815-5876

Email: naharvinayak@gmail.com

\section{References:}

1. Fisher, G. J., Wang, Z., Datta, S. C., Varani, J., Kang, S., \& Voorhees, J. J. (1997).

Pathophysiology of Premature Skin Aging Induced by Ultraviolet Light. New England Journal of Medicine, 337(20), 1419-1429. doi:10.1056/nejm199711133372003

2. Gilchrest, B., \& Yaar, M. (1992). Ageing and photoageing of the skin: Observations at the cellular and molecular level. British Journal of Dermatology, 127(S41), 25-30. doi:10.1111/j.1365-2133.1992.tb16984.x

3. Yaar, M., Eller, M. S., \& Gilchrest, B. A. (2002). Fifty Years of Skin Aging. Journal of Investigative Dermatology Symposium Proceedings, 7(1), 5158. doi:10.1046/j.1523-1747.2002.19636.x

4. Fisher, G. J., Kang, S., Varani, J., Bata-Csorgo, Z., Wan, Y., Datta, S., \& Voorhees, J. J. (2002). Mechanisms of Photoaging and Chronological Skin Aging. Archives of Dermatology, 138(11). doi:10.1001/archderm.138.11.1462

5. Media Centre - IARC News. (n.d.). Retrieved from https://www.iarc.fr/en/mediacentre/iarcnews/2009/sunbeds_uvradiation.php

6. Green, A. C., Wallingford, S. C., \& Mcbride, P. (2011). Childhood exposure to ultraviolet radiation and harmful skin effects: Epidemiological evidence. Progress in Biophysics and Molecular Biology, 107(3), 349-355. doi:10.1016/j.pbiomolbio.2011.08.010

7. Miller, D. L., \& Weinstock, M. A. (1994). Nonmelanoma skin cancer in the United States: Incidence. Journal of the American Academy of Dermatology, 30(5), 774-778. doi:10.1016/s01909622(08)81509-5

8. Mackie, R. M., \& Aitchison, T. (1982). Severe sunburn and subsequent risk of primary cutaneous malignant melanoma in scotland. British Journal of Cancer, 46(6), 955960. doi:10.1038/bjc. 1982.307

9. Zanetti, R., Franceschi, S., Rosso, S., Colonna, S., \& Bidoli, E. (1992). Cutaneous melanoma and sunburns in childhood in a Southern European population. European Journal of Cancer, 28(6-7), 1172-1176. doi:10.1016/0959-8049(92)90480-p

10. Diffey, B., \& Cheeseman, J. (1992). Sun protection with hats. British Journal of Dermatology, 127(1), 10-12. doi:10.1111/j.13652133.1992.tb14816.x

11. Coyne, E. Q., Lichtman, M. K., Simons, J., Sarkar, A. K., \& Rünger, T. M. (2018). In vitro assessment of the broad-spectrum ultraviolet protection of clothing. Journal of the American Academy of Dermatology, 79(2), 373-375. doi:10.1016/j.jaad.2017.12.078

12. Linos, E., Keiser, E., Fu, T., Colditz, G., Chen, S., \& Tang, J. Y. (2011). Hat, shade, long sleeves, or sunscreen? Rethinking US sun protection messages based on their relative effectiveness. Cancer Causes \& Control, 22(7), 1067-1071. doi:10.1007/s10552-011-9780-1

13. Gambichler, T., Hatch, K. L., Avermaete, A., Altmeyer, P., \& Hoffmann, K. (2002). Influence of wetness on the ultraviolet protection factor (UPF) of textiles: In vitro and in vivo measurements. Photodermatology, Photoimmunology and Photomedicine, 18(1), 2935. doi:10.1034/j.1600-0781.2002.180105.x

14. Montague, M., Borland, R., \& Sinclair, C. (2001). Slip! Slop! Slap! and SunSmart, 1980-2000: Skin Cancer Control and 20 Years of PopulationBased Campaigning. Health Education \& Behavior,28(3), 290-305. doi:10.1177/109019810102800304

15. Hughes, M., Williams, G., Baker, P., \& Green, A. (2013). Sunscreen and Prevention of Skin Aging. Annals of Internal Medicine, 158(11). doi:10.7326/0003-4819-158-11-20130604000001

16. Center for Drug Evaluation and Research. (n.d.). Understanding Over-the-Counter Medicines Questions and Answers: FDA announces new requirements for over-the-counter (OTC) sunscreen products marketed in the U.S. Retrieved from

https://www.fda.gov/drugs/resourcesforyou/consu mers/buyingusingmedicinesafely/understandingo ver-the-countermedicines/ucm258468.htm

17. Center for Drug Evaluation and Research. (n.d.). Consumer Updates - Sunscreen: How to Help Protect Your Skin from the Sun. Retrieved from https://www.fda.gov/ForConsumers/ConsumerUp dates/ucm239463.htm

18. Norris, J. F. (1996). Sunscreens, suntans, and skin cancer. Bmj, 313(7062), 941-942. doi:10.1136/bmj.313.7062.941d

19. Ekstein, N. (2018, July 19). This Bizarre Sunscreen Booth Is Driving Cocktail Sales at Hotel Pools. Retrieved from

May 2020 Volume 4 Issue 3 
https://www.bloomberg.com/news/articles/201807-19/this-bizarre-sunscreen-booth-is-drivingcocktail-sales-at-hotel-pools

20. Sambandan, D. R., \& Ratner, D. (2011). Sunscreens: An overview and update. Journal of the American Academy of Dermatology, 64(4), 748-758. doi:10.1016/j.jaad.2010.01.005

21. UVA \& UVB. (n.d.). Retrieved from https://www.skincancer.org/prevention/uva-anduvb

22. Heurung, A. R., Raju, S. I., \& Warshaw, E. M. (2014). Adverse Reactions to Sunscreen Agents: Epidemiology, Responsible Irritants and Allergens, Clinical Characteristics, and Management. Dermatitis, 25(6), 289-326. doi:10.1097/der.0000000000000079

23. Monteiro-Riviere, N. A., Wiench, K., Landsiedel, R., Schulte, S., Inman, A. O., \& Riviere, J. E. (2011). Safety Evaluation of Sunscreen Formulations Containing Titanium Dioxide and Zinc Oxide Nanoparticles in UVB Sunburned Skin: An In Vitro and In Vivo Study. Toxicological Sciences, 123(1), 264-280. doi:10.1093/toxsci/kfr148

24. Cross, S. E., Innes, B., Roberts, M. S., Tsuzuki, T., Robertson, T. A., \& Mccormick, P. (2007). Human Skin Penetration of Sunscreen Nanoparticles: In-vitro Assessment of a Novel Micronized Zinc Oxide Formulation. Skin Pharmacology and Physiology, 20(3), 148-154. doi:10.1159/000098701

25. Foley, P., Nixon, R., Marks, R., Frowen, K., \& Thompson, S. (1993). The frequency of reactions to sunscreens: Results of a longitudinal population-based study on the regular use of sunscreens in Australia. British Journal of Dermatology, 128(5), 512-518. doi:10.1111/j.1365-2133.1993.tb00227.x

26. Final Report on the Safety Assessment of Urocanic Acid. (1995). Journal of the American College of Toxicology, 14(5), 386-423. doi:10.3109/10915819509083599

27 Schneider, L. S., \& Lim, W. H. (2018). Review of environmental effects of oxybenzone and other sunscreen active ingredients. Journal of the American Academy of Dermatology

28. PDF. (n.d.). South Florida, Hawaii, U.S. Virgin Islands, American Samoa: National Park Service U.S. Department of the Interior.

29. Jung, K., Seifert, M., Herrling, T., \& Fuchs, J. (2008). UV-generated free radicals (FR) in skin: Their prevention by sunscreens and their induction by self-tanning agents. Spectrochimica Acta Part A: Molecular and Biomolecular Spectroscopy, 69(5), 1423-1428. doi:10.1016/j.saa.2007.09.029
30. O'Leary, R. E., Diehl, J., \& Levins, P. C. (2014). Update on tanning: More risks, fewer benefits. Journal of the American Academy of Dermatology, 70(3), 562-568. doi:10.1016/j.jaad.2013.11.004

31. Pagoto, S. L., Schneider, K. L., Oleski, J., Bodenlos, J. S., Merriam, P., \& Ma, Y. (2009). Design and methods for a cluster randomized trial of the Sunless Study: A skin cancer prevention intervention promoting sunless tanning among beach visitors. BMC Public Health, 9(1). doi:10.1186/1471-2458-9-50

32. Garone, M., Howard, J., \& Fabrikant, J. (2015). A Review of Common Tanning Methods. The Journal of Clinical Aesthetic Dermatology, 8(21), 43-47.

33. Barsh, G., \& Attardi, L. (n.d.). A Healthy Tan? The New England journal of medicine., 356(21), 2208-2210. doi:10.1056/NEJMcibr071775

34. Mahler, H. I., Kulik, J. A., Gerrard, M., \& Gibbons, F. X. (2007). Long-term effects of appearancebased interventions on sun protection behaviors. Health Psychology, 26(3), 350-360. doi:10.1037/0278-6133.26.3.350

35. Tuong, W., \& Armstrong, A. W. (2014). Effect of appearance-based education compared with health-based education on sunscreen use and knowledge: A randomized controlled trial. Journal of the American Academy of Dermatology, 70(4), 665-669. doi:10.1016/j.jaad.2013.12.007

36. Hillhouse, J., \& Turrisi, R. (2002). Examination of the efficacy of an appearance-focused intervention to reduce UV exposure. Journal of behavioral medicine., 25(4), 395-409. doi:10.1023/A:1015870516460

37. Mahler, H. I., Kulik, J. A., Gibbons, F. X., Gerrard, M., \& Harrell, J. (2003). Effects of appearancebased intervention on sun protection intentions and self-reported behaviors. Health Psychology,22(2), 199-209. doi:10.1037//02786133.22.2.199

38. Brinker, T. J., Faria, B. L., Gatzka, M., Faria, O. M., Heppt, M. V., Kirchberger, M. C., . . . Bernardes-Souza, B. (2018). A skin cancer prevention photoageing intervention for secondary schools in Brazil delivered by medical students: Protocol for a randomised controlled trial. BMJ Open, 8(3). doi:10.1136/bmjopen2017-018299

39. Armstrong, A., Watson, A., Makredes, M., Frangos, J., Kimball, A., \& Kvedar, J. (n.d.). TextMessage Reminders to Improve Sunscreen Use. Archives of dermatology., 145(11). doi:10.1001/archdermatol.2009.269

May 2020 Volume 4 Issue 3 